\title{
BMJ Open Infectious complications of endoarterial interventional radiology: protocol for an observational study of a longitudinal national cohort of patients assessed in the French hospital discharge database (MOEVA study)
}

Kaoutar Aid Mellouk, ${ }^{1}$ Abdelmajid Soulaymani, ${ }^{1}$ Fei Gao, ${ }^{2}$ Pascal Astagneau, $, 3,4$ Benoit Misset ${ }^{5,6}$

To cite: Aid Mellouk K, Soulaymani A, Gao F, et al. Infectious complications of endoarterial interventional radiology: protocol for an observational study of a longitudinal national cohort of patients assessed in the French hospital discharge database (MOEVA study). BMJ Open 2019;9:e024181. doi:10.1136/ bmjopen-2018-024181

- Prepublication history for this paper is available online. To view these files, please visit the journal online (http://dx.doi org/10.1136/bmjopen-2018024181).

Received 14 May 2018 Revised 2 January 2019 Accepted 16 January 2019

Check for updates

(C) Author(s) (or their employer(s)) 2019. Re-use permitted under CC BY-NC. No commercial re-use. See rights and permissions. Published by BMJ.

For numbered affiliations see end of article.

Correspondence to

Kaoutar Aid Mellouk

kaoutarmellouk92@gmail.com

\section{ABSTRACT}

Around seven million patients undergo endoarterial interventional radiology procedures (EAIRP) annually worldwide. These procedures have become part of the standard repertoire of vascular surgery. However, the healthcare-associated infections related to these procedures are relatively unknown. Prevalence and adverse outcome of infectious complication (IC) post-EAIRP may be underestimated. We aim to provide national trend estimation of EAIRP incidence and outcome in France. Methods and analysis From the French Common Classification of Medical Acts, we will define four categories of EAIRP. We will collect procedures via the French nationwide hospital discharge database, called Programme de Médicalisation des Systèmes d'Information (PMSI) and derived from the Diagnosis Related Group system. Various combinations to identify the numerator will be employed according to a pre-established algorithm. Technical data wrangling tools facilitating the use of PMSI will be developed to obtain a clean and well-structured database ready for statistical analysis. This protocol will require competences in medicine, epidemiology, statistics, data processing and techniques through various stages of the study. The cohort will contain the denominator (the first act of the first stay of each patient) and the corresponding numerator (the IC which will occur during the first stay). Ethics and dissemination No nominative, sensitive or personal data on patients have been collected. The study of the MOrtality and infectious complications of therapeutic EndoVAscular interventional radiology (MOEVA) study does not involve humans, and falls within the scope of the French Reference Methodology MR-004 according to 2016-41 law dated 26 January 2016 on the modernisation of the French health system. Our study involves the reuse of already recorded data, which require neither information or non-opposition of the included individuals. Access to linked ANOnymous (ANO) file in the PMSI databases was approved by the French National Commission for Data Protection and Liberties (CNIL number 1564135). The results will be disseminated through a peer-reviewed publication.

\section{Strengths and limitations of this study}

- The large sample size of Programme de Médicalisation des Systèmes d'Information (PMSI) enables analyses of rare conditions, uncommon treatments and special patient populations spanning several years of recruitment.

- The PMSI's database is immediately available and systematically collected over time.

- The chosen French Common Classification of Medical Acts' codes reflect homogeneous population selected for endoarterial interventional radiology procedure treatment evaluation.

- Infectious diseases coding is heterogeneous across clinicians within the PMSI's framework because they are more often secondary than principal diagnoses during a single stay.

\section{INTRODUCTION}

Cardiovascular (CV) diseases are the leading cause of mortality in the world, representing 17.5 million deaths per year, that is, $31 \%$ of world mortality. ${ }^{1}$ In France, in 2011, CV diseases accounted for $27 \%$ of the total deaths, ${ }^{2}$ and the mean age was 71 years. ${ }^{3}$ Vascular disease, affecting the vascular system (arteries, veins and lymphatic circulation), is a pathological state triggered by endothelial cell dysfunction ${ }^{4}$ and a subgroup of CV diseases. Today the three components to treat this high-risk disease include medical treatment, intensive management of risk factors, and surgery or endovascular interventional radiology (IR). ${ }^{56}$ Annually, around seven million patients undergo percutaneous interventional vascular procedures worldwide, and this number is expected to escalate further in the coming years. ${ }^{7}$ 
IR is a clinically oriented specialty that employs image guidance in order to perform minimally invasive diagnostic and therapeutic procedures. ${ }^{89}$ Using innovative, evolving and often complex techniques, IR has revolutionised patient care, reducing morbidity and mortality and allowing more rapid recovery.

IR encompasses a wide range of procedures and techniques. On the one hand, endovenous interventional radiology procedures available for treatment of lower extremity venous insufficiency include endovenous laser ablation, radiofrequency endovascular ablation, inferior vena cava filter placement, central venous access and sclerotherapy. ${ }^{10}$ On the other hand, endoarterial interventional radiology procedures (EAIRPs) include diagnostic angiography, angioplasty, thrombolysis, arterial closure device placement, stent placement, end-graft placement, embolisation and chemoembolisation, uterine artery embolisation, and transjugular intrahepatic portosystemic shunt. ${ }^{11}$

EAIRP, as a surgical activity, is susceptible to risk of infection, which varies according to the state of the patient and whether a established medical device is used or not. ${ }^{5}$ Its practical implementation depends on individual and collective behaviours, organisation, ${ }^{12}$ general constraints of hygiene ${ }^{13}$ of image-guided of IR equipment and radiation protection. ${ }^{14}$ The complexity and multiplicity of the procedures, the severity of the patient's disease and the need for optimal result are reasons for monitoring ${ }^{15}$ and evaluation of all steps of the interventions. ${ }^{516}$ Today, we have limited insights into the underlying infectious complication (IC) mechanisms post-EAIRP, ${ }^{17} 18$ so we hypothesised that the prevalence and death from IC post-EAIRP are underestimated because previous estimations were not based on global databases, such as national databases.

Surveillance of healthcare-associated infections (HAIs) is now key to prevention and an effective element in the fight against HAIs. ${ }^{19}$ Because monitoring is often time-consuming and labour-intensive,${ }^{20}$ only some studies estimated the prevalence of HAIs post-EAIRP. Malavaud $e t$ al have estimated the risk as $0.64 \%$ for coronary angioplasty and $4.9 \%$ for all arterial and venous angioplasties. ${ }^{152}$ Other studies have reported the occurrence of prosthetic vascular graft infection with a cumulative incidence varying from $0.5 \%$ to $5 \%^{22}{ }^{23}$ and from $0 \%$ to $3.1 \%{ }^{24}$ Data were heterogeneous ${ }^{25}$ and associated with a low level of evidence. ${ }^{26}$ Most studies were monocentric $^{27}$ and provided information on a particular microbial ecology and cannot be extrapolated to another centre. ${ }^{6}$

The Programme de Médicalisation des Systèmes d'Information (PMSI) database ${ }^{28}$ which collects hospital discharge data (HDD), represents an important potential for epidemiology, with a positive cost/quality ratio since the data were already recorded. Henceforth, surveillance and measurement of healthcare are increasingly based on risk-adjusted outcomes derived from administrative databases. ${ }^{29}$ This is why researchers and policy makers use HDD to identify, track and analyse national trends in healthcare utilisation, access, charges, quality and outcomes. ${ }^{30}$
In France, the PMSI is an annual database of hospital inpatient stay. It is the largest, publicly available, all-payer inpatient care database. On mandatory use, ${ }^{31}$ it generates 25 million stays per year. ${ }^{32}$ In 1996 the PMSI was adapted from the Diagnosis Related Group (DRG) of the USA. The PMSI is used to create billing data submitted by hospitals to the state. DRG includes information on clinical and resource use mainly available from discharge abstracts. ${ }^{33}$ DRG is designed to deliberately classify groups of stays according to medical similarity and cost. ${ }^{34}$ In most hospitals, the processing of information on medical records, which is then entered into databases for later analysis, follows a typical sequence. The medical activity reported by the PMSI is entered by coding the summary discharge of hospitals, which contains alphanumeric codes for (1) diagnoses according to the International Classification of Diseases, Tenth Revision (ICD-10) in its French version and (2) the French Common Classification of Medical Acts (FCCMA). ${ }^{35}$ Thus, the FCCMA allows billing of hospital activity relative to payment of fees.

The use of PMSI databases with specific architecture in an epidemiological context puts researchers and engineer face the complexity of handling these data. This complexity largely exceeds the number of individuals and variables. To decipher them, these data require structuring, cleaning, enrichment, pairing, concatenation, merge, recoding, analysis and validation across special software application before interpretation of findings.

Even if research in the field is developing, it remains discrete, and exploitation of national medicoeconomic databases for studies of the French PMSI is insufficient. To date, these preliminary treatments and protocols for PMSI exploitation are not standardised. They are reiterated in each study and involve a time-consuming implementation. To help develop improved methods to increasingly use PMSI data, we created a methodologiy for design of a PMSI cohort lends to the analysis. Our research question is the following: 'What is the incidence of the IC of EAIRP?'

\section{Objectives}

The primary objective is to determine the epidemiology of IC secondary to EAIRP within 30 days of the procedure. The secondary objectives are (1) to identify the denominator, numerator and all records relating to the same individual using record linkage, (2) to assess clinical outcomes across four therapeutic approaches in different study populations (children and adults), and (3) to compare the characteristics of the patients who underwent EAIRP and developed IC with the same population without IC.

\section{METHODS AND ANALYSES}

\section{Data source}

The source of data was the French PMSI database in medicine, surgery and obstetrics from 2009 to 2014. 


\section{Study design}

MOrtality and infectious complications of therapeutic EndoVAscular interventional radiology (MOEVA) is an observational study of the longitudinal national cohort of all patients hospitalised in French public and private hospitals and assessed in the PMSI database. Patients will be selected by the presence in the hospital discharge data set, from 1 January 2009 through 31 December 2014, of at least one EAIRP according to the FCCMA. In accordance with the French national regulations, due to the absence of direct involvement of patients and the retrospective nature of the study design, informed consent is not required. The PMSI's tables will be linked using the unique encrypted ANOnymous (ANO) possible since $2001{ }^{36}$ Each pathway patient will be studied for 24 months (figure 1).

The PMSI database contains data assessing a person's consumption of care, and information on insurance, healthcare institutions and health professionals. ${ }^{37}$ Each record is for a single hospitalisation; thus, multiple records are possible for an individual with recurrent hospitalisations. For this study, we will use the Anonymous Summary
Discharge (Résumé de Sortie Anonyme).$^{37}$ The files used are those resulting from the validation of the national Technical Agency of Hospitalisation Information (Agence Technique de l'Information sur l'Hospitalisation).

\section{Patient and public involvement}

The research question has been developed from prior feedback experience from practising physicians who are piloting the study. Besides, also referring to the national French surveillance system for control of nosocomial infections, very few notifications of IC have been reported for the last 10 years. Hence, we decided to provide the current state of knowledge on the morbimortality of IC after therapeutic EAIRP. In this framework of study, patients and the public were not actively involved in the research question ${ }^{38}$ and protocol development, including outcome measures. Specific patient advisers were not consulted for this study. The results of this study, which is of public interest, will be disseminated through the CPias (Centre d'appui pour la Prévention des Infections Associées aux Soins) internally, and through publication of the final report at national and international levels.

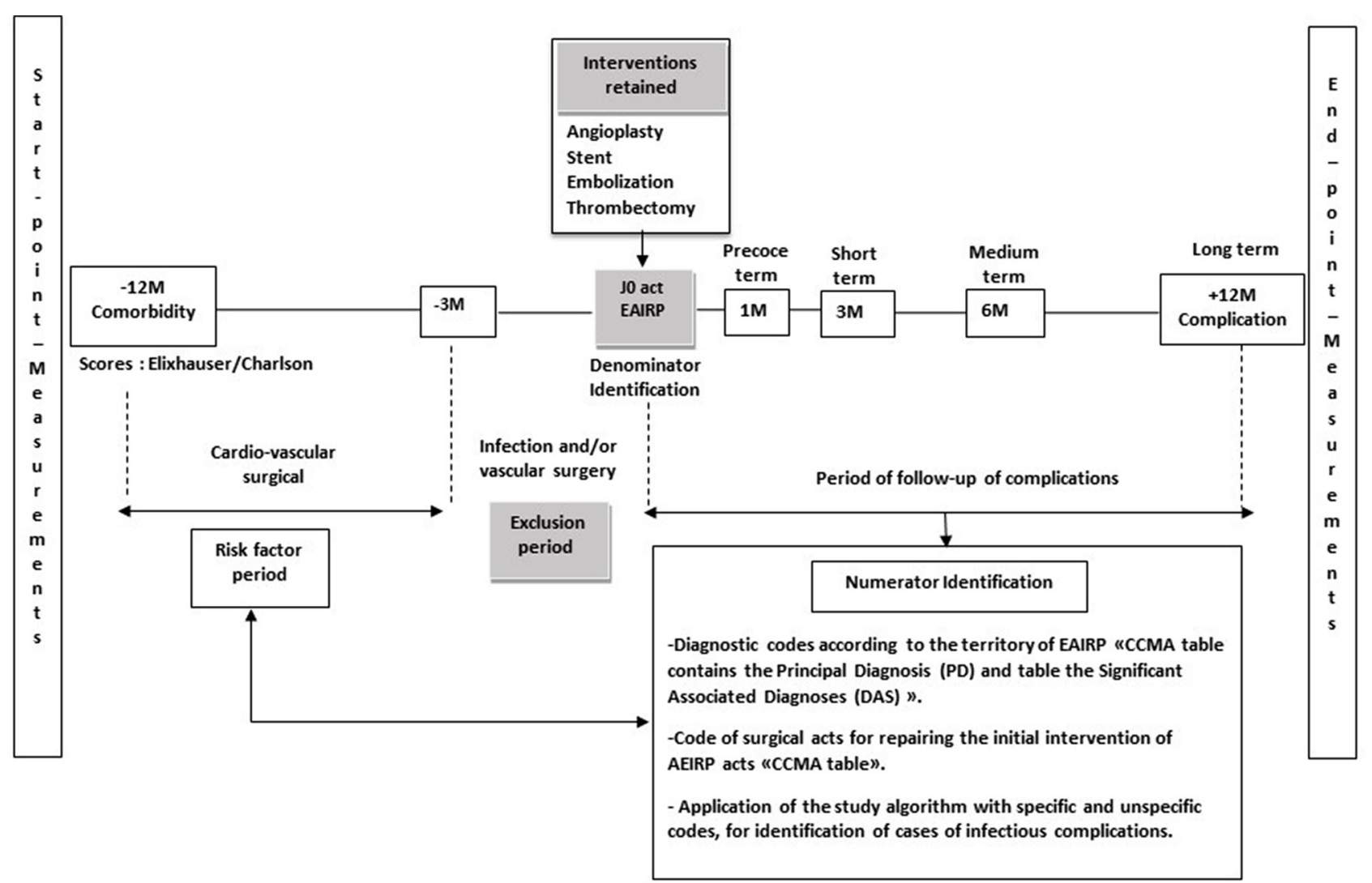

Figure 1 Chronological description of patient pathway with endoarterial interventional radiology procedures (EAIRP). Subjects who had an EAIRP with one of the interventions retained in the study will be screened for denominator's eligibility. Only those who developed at least an infectious complication will be retained for statistics analysis. The definition of infectious complication (IC) follows an algorithm of case. The checkpoints of IC will be applied to 7 days and 1, 3, 6 and 12 months after EAIRP. If cardiovascular (CV) intervention occurred between 12 and 9 months before EAIRP, it will be regarded as a risk factor. If $\mathrm{CV}$ intervention occurred during 3 months before EAIRP, it will be excluded from statistical analysis. If the CV intervention will occur after EAIRP, this one will be counted among the complications and will be regarded as a repair act of the initial act. The follow-up of each patient will be made over 24 months. 12-month feedback before EAIRP for the collection of the comorbidities according to the scores of Elixhauser and Charlson. FCCMA, French Common Classification of Medical Acts. 
This work is articulated around five steps.

\section{Step 1: study population}

The study consists of patients whose hospital stay was related to a first EAIRP.

Identification of vascular diseases and EAIRP interventions

The main arterial vascular disease categories ${ }^{1}$ are the following: (1) coronary artery disease (also known as coronary heart disease and ischaemic heart disease); (2) peripheral arterial disease, disease of the blood vessels that supply blood to the arms and legs; (3) cerebrovascular disease, disease of the blood vessels that supply blood to the brain (includes stroke); (4) renal artery stenosis, narrowing of the renal arteries that carry blood to the kidneys from the aorta; and (5) aortic aneurysm.

The definition of EAIRP is specified in the FCCMA. It consists of the classifying acts that are mandatory in stays summary. ${ }^{33}$ These are coded at the end of each intervention by the physician who performed the IR act. All of these acts are refundable. To find a specific act, several strategies are possible. We will search use of above-mentioned list of acts in the totality of FCCMA V.41. ${ }^{39}$ All codes which will belong to the category of acts 'by percutaneous trans-arterial route' (table 1). The billing records from each IR will be identified and reviewed by two of the authors (AKM and BM).

\section{Eligibility criteria for the denominator's definition}

The extraction of stays with at least one code linked with an EAIRP act (FCCMA code) will be carried out by the data manager of the French School for Advanced Studies in Public Health (Ecole des Hautes Etudes en Santé Publique) based in Rennes, France. These codes will result from the baseline assessment of eligibility criteria (box 1). After the reception of the PMSI database, we will apply a second wave of exclusion directly on stays of patients. Full and detailed study eligibility criteria are listed in box 1 .

\section{Step 2: study outcome}

The study is based on hospital stays with at least one complication.

\section{Primary endpoints}

The primary outcome is the incidence of IC or all-cause mortality within 30 days after EAIRP.

\section{Identification and definition of IC}

In the absence of a specific definition of HAIs related to IR, we will adapt the definition of surgical site infection ${ }^{40}$ : 'infection occurs within 30 days after the operation if no implant is left in place or within oneyear if implant is in place and the infection appears to be related to the operation and infection involves any part of the anatomy (eg, organs and spaces) other than the incision which was opened or manipulated during an operation'. The selection of antibiotic prophylaxis (AP) during the IR procedures indicates that $\mathrm{AP}$ was largely guided by the existing surgical literature. ${ }^{41}{ }^{42}$ The risks of infection of open surgical procedures differ from those of the IR procedures. ${ }^{43}$ In the PMSI database, the IC will be identified by diagnostic codes. ${ }^{44}$

The identification of keywords of CV infection post-IR was made by a working group within the Centre for Support and Prevention of Infections associated with Health Care (CPias). We have readjusted a pre-established algorithm and was validated by this team. ${ }^{45}{ }^{46} \mathrm{In}$ agreement with other studies, ${ }^{20}$ we retained keywords such as 'bacteremia', 'abscess', 'sepsis', 'septic shock',

Table 1 Different codes for identification of the denominator according to FCCMA V.41

\section{Denominator's codes}

\begin{tabular}{|c|c|}
\hline Procedures & Codes \\
\hline \multicolumn{2}{|c|}{ Codes of EAIRP act-FCCMA V.41 } \\
\hline Angioplasty & $\begin{array}{l}\text { DDFF001, DDFF002, EDAF007, EDAF009, DGAF006, DGAF003, DDAF001, DDAF010, DGAF001, } \\
\text { ECAF003, EBAF004, EBAF009, EBAF003, EBAF005, EBAF013, EAAF903, EAAF004, EAAF901, ECAF002, } \\
\text { ECPF003, DGAF008, EDAF002, EDPF008, EDAF008, EDAF004, EDPF007, EEAF003, EEAF001, EEAF005, } \\
\text { EEPF002, ENAF002, EDPF003, EZQH002, ECPF004, EDPF002, EBAF009, BAF001. }\end{array}$ \\
\hline $\begin{array}{l}\text { Angioplasty with } \\
\text { stent }\end{array}$ & $\begin{array}{l}\text { DDPF002, EBAF011, EDAF010, EELF002, DGAF004, DDAF003, DDAF004, DDAF006, DDAF007, DDAF008, } \\
\text { DDAF009, DGAF007, DGLF003, ECAF004, ECLF004, ECPF005, EBAF010, EBAF001, EBAF006, EAAF902, } \\
\text { EBAF014, EAAF002, EAAF900, ECLF003, ECAF001, ECPF001, ECPF002, DGAF005, EDAF003, EDPF009, } \\
\text { DGPF002, EDPF006, DGLF005, DGLF002, DGLF001, EDLF004, EDLF006, EDAF005, EDLF008, EEAF006, } \\
\text { EDAF001, EDAF006, EDLF007, EDPF001, EDLF005, EFAF004, EEPF001, EDPF005, ENAF001, EDPF004, } \\
\text { EDLF013, DBLF001, DGLF012, EEAF002. }\end{array}$ \\
\hline Embolisation & $\begin{array}{l}\text { EASF014, EASF004, EDSF005, EDSF006, EDSF012, EDSF015, EDSF003, EDSF008, EDSF016, EDSF004, } \\
\text { ECSF008, EDSF014, DFSF002, ECSF004, ECSF006, EBSF003, EBSF004, ECSF002, EESF007, EESF006, } \\
\text { EESF004, EDSF011, EESF001, DDSF001, EDSF001, EDSF009, EDSF007, EDSF013, EDSF002, EDSF010, } \\
\text { ECSF001, ECSF003, EESF005, EASF007, EASF011. }\end{array}$ \\
\hline Thrombectomy & $\begin{array}{l}\text { EBNF001, EBNF002, EDJF001, ENFF001, EDNF003, ENNF001, ECJF001, DGPF001, EEJF001, EDJF002, } \\
\text { EENF001, EDNF001, EENF002, ECNF001, ECNF002, EDNF002. }\end{array}$ \\
\hline
\end{tabular}

EAIRP, endoarterial interventional radiology procedures; FCCMA, French Common Classification of Medical Acts. 


\section{Box 1 Study inclusion and exclusion criteria}

Inclusion criteria at baseline.

- Hospital stay for EAIRP between 2009 and 2014 (see figure 1).

- Age older than 1 year.

- Percutaneous angioplasty without a stent (limbs, supra-aortic trunks (SAT) and carotids).

- Percutaneous angioplasty with stent placement (endoprosthesis: limbs, SAT, carotids; endoprosthesis covered thoracic aorta, abdominal aorta, peripheral vessels).

- Percutaneous embolisation (embolisation vaso-occlusion and/or endovascular sclerotherapy (limbs, SAT and carotid) and intra-arterial embolisation).

- Percutaneous thrombectomy and thromboaspiration (in situ thrombolysis: peripheral arteries, intracranial visceral arteries).

Exclusion criteria relative to IR procedure.

- IR procedure carried out in a venous territory.

- Act which is not exclusively arterial.

- Act which is exclusively diagnostic.

- Therapeutic act with injection of anticancer chemotherapy.

- Extraction of intravascular or intracardiac foreign bodies.

- Arterial access with plantable port for chemotherapy embolisation.

- Stays comprising only FCCMA of 'diagnostic radiology' without other acts of EAIRP in the denominator.

\section{Other exclusion criteria.}

- Residence out of France (foreign postal code, not allowing follow-up of the patient after the EAIRP act).

- Code of the following major diagnostic categories (Categories Majeures de Diagnostic): (1) code 90: error and other uncategorised or ungroupable stays; (2) code 28: session (specific health interventions undertaken by health professionals, for example, chemotherapy and dialysis); and (3) code 15: newborn and other neonates (perinatal period).

- Palliative care during EAIRP: palliative care will be identified using the ICD-10 (code 251.5), which includes end-of-life care and terminal care.

- Infection within 3 months before EAIRP.

- Vascular surgery within 3 months before EAIRP.

- Exclusion of combined surgical and IR interventions.

- Hospital stays which exceed 12 months (because the follow-up is limited to 12 months; figure 1).

- Other stays than the first one (only the first EAIRP will be studied).

EAIRP, endoarterial interventional radiology procedures; FCCMA, French Common Classification of Medical Acts; ICD-10, International Classification of Diseases, Tenth Revision; IR, interventional radiology.

'drainage', 'wound', 'infection of the point of puncture', 'infection of surgical site', 'nosocomial infection' and 'infection acquired at the hospital'. All infections (bacterial and fungus infections) will be considered.

Based on these keywords, we identified two lists of diagnostic codes of infection from ICD-10. The first list will include either the pathogen agent or the anatomical location of infection. We called this list 'specific-code'. The second list will include codes of inflammation embolic of mechanic lesions which may be imputed to infection. We called this list 'unspecific-code' (table 2).

The identification of hospital stay for infection postEAIRP will be based on a pre-established algorithm. This will select the cases based on the presence of diagnosis codes in the ICD-10 (specific code, unspecific code), which we will associate with to other surgical acts of the FCCMA qualified of the repairer of the initial act. The surgical repair act will be called specific act of infection post-EAIRP (table 2).

This algorithm will be applied to those patients who were retained after the denominator's eligibility criteria. The identification of hospital stay with infection will be carried out by application of these lists of diagnostic codes (specific code, unspecific code) in principal diagnosis and/or secondary, significant associated diagnoses (DAS) (Diagnostic Associé Significatif), associated or not with a surgical repair act. The use of both Diagnosis Principal (DP) and DAS codes aims at circumventing the poor inter-rater reliability of the DP choice for infectious diseases. ${ }^{47}$ We identified seven combinations of codes to define possible of certain infection cases (table 3).

\section{Secondary endpoints}

Secondary outcomes will be defined as any of the following:

- Conversion to surgical repair.

- Postprocedural complication.

- Total length of intensive care unit stay and Simplified Acute Physiology Score (SAPS II).

- Hospital length of stay.

- Readmission.

- Mortality, up to 3 and 12 months, if the patient dies in the hospital.

\section{Step 3: study comorbidities}

A period of 12 months prior to hospitalisation concerning the realisation of EAIRP will be considered in recovering data on patients' comorbidities. ${ }^{48}$ Comorbidity may be defined as the total burden of illnesses unrelated to the principal diagnosis. ${ }^{49}$ To achieve complete data processing, we will use two comorbidity measurement tools adapted for use with the ICD-10 and nature of administrative data ${ }^{50}$ : Charlson score is a weighted index of comorbidities built to predict mortality at 1 year. ${ }^{51}$ This score is built around 17 comorbidities using clinical conditions recorded in charts. Elixhauser score is used to classify comorbidities among inpatients in order to predict hospital mortality. ${ }^{50}$ This score is built around 30 comorbidities using distinctive ICD-10 codes as a starting point. We also proceed to calculate the number of diseases per patient. This last approach is defined by the notion of multimorbidity. ${ }^{52}$

\section{Step 4: study follow-up}

Subjects will be followed during their postprocedure stay at hospital. Follow-up of IC will be carried out at various periods according to the European recommendations in progress. $^{53}$

- For all EAIRP:

- During stay of the procedure.

- During the 7 days which follow the procedure.

- One month after the procedure. 
Table 2 Codes used to document infectious complication post-EAIRP in ICD-10 and FCCMA classifications

\section{Numerator's codes}

Intervention/Diagnosis /

Acts

\section{Codes}

Diagnosis codes of the ICD-10

Specific code

R572, A483, A021, A022, A028, A030, A038, A039, B377, B378, B379, L022, L024, L980, M016, M130, M138, M680, M902, A400, A401, A402, A403, A408, A409, A410, A411, A412, A413, A414, A415, A418, A419, A488, A490, A491, A492, A498, A499, B950, B951, B952, B953, B954, B955, B956, B957, B958, B961, B962, B963, B964, B965, B966, B967, B968, B99+0, B99+1, I330, I38, I398, I339, I301, M462, M4620, M4621, M4622, M4623, M4624, M4625, M4626, M4627, M4628, M4629, M463, M4630, M4632, M4633, M4634, M4635, M4636, M4637, M4639, M464, M4640, M4642, M4643, M4644, M4645, M4646, M4647, M4649, M492, M4920, M4921, M4922, M4923, M4924, M4925, M4926, M4927, M4928, M4929, M000, M0000, M0001, M0002, M0003, M0004, M0005, M0006, M0007, M0008, M0009, M002, M0020, M0021, M0022, M0023, M0024, M0025, M0026, M0027, M0028, M0029, M008, M0080, M0081, M0082, M0083, M0084, M0085, M0086, M0087, M0088, M0089, M009, M0090, M0091, M0092, M0093, M0094, M0095, M0096, M0097, M0098, M0099, M013, M0130, M0131, M0132, M0133, M0134, M0135, M0136, M0137, M0138, M0139, M018, M0180, M0181, M0182, M0183, M0184, M0185, M0186, M0187, M0188, M0189, M032, M0320, M0321, M0322, M0323, M0324, M0325, M0326, M0327, M0328, M0329, M651, M6510, M6511, M6512, M6513, M6514, M6515, M6516, M6517, M6518, M6519, M726, M7260, M7261, M7262, M7263, M7264, M7265, M7266, M7267, M7268, M7269, M6000, M6001, M6002, M6003, M6004, M6005, M6006, M6007, M6008, M6009, M860, M8600, M8601, M8602, M8603, M8604, M8605, M8606, M8607, M8608, M8609, M861, M8610, M8611, M8612, M8613, M8614, M8615, M8616, M8617, M8618, M8619, M868, M8680, M8681, M8682, M8683, M8684, M8685, M8686, M8687, M8688, M8689, M869, M8690, M8691, M8692, M8693, M8694, M8695, M8696, M8697, M8698, M8699.

Unspecific code I248, I249, I259, I740, I741, I742, I743, I744, I745, I748, I749, I770, R502, R508, R509, R650, R651.

FCCMA

Specific act: for repair of the initial

EAIRP acts
DCJA001, DCJA002, DCJA003, DCJA004, DCJA005, DCJA006, DCJA007, DCJA008, DCJA009, DCJA010, DCJA011, DCJA012, DCJA013, DCJA014, DCJA015, DCJA016, DCJA017, DCJA018, DCJA019, DCJA020, DCJA021, DCJA022, DCJA023, DCJA024, DCJA025, DCJA026, DCJA027, DCJA028, DCJA029, DCJA030, DCJA031, DCJA032, DCJA033, QBFA014, QZQA001, ZZQL011, ZZQL015, QZJA001, QZJA002, QZJA012, QZJA013, QZJA015, QZJA016, QZJA017, QZJA023, ECFA006, EDFA010, EDFA009, EDKA002, EDKA003, EDPA001, EDSA002, EDSA003, EZSA003, ECMA001.

EAIRP, endoarterial interventional radiology procedures; FCCMA, French Common Classification of Medical Acts; ICD-10, International Classification of Diseases, Tenth Revision.

- Only for the angioplasty with stent:

- 3 months after the procedure.

- 12 months after the procedure.

\section{Step 5: general guidelines for cohort identification}

The PMSI is distributed as fixed-width American Standard Code for Information Interchang (ASCII)-formatted data files or tables compressed with WinZip. After the delivery of the PMSI database, we will begin the examination of the four tables in the following order: Common Classification of Medical Acts (CCMA), stay, medical unit (MU) and DAS. At this stage those tables are individually clean, and they are supposed to contain non-redundant data (figure 2).

Table 3 Combinations of codes for the diagnoses of infectious complications following EAIRP

\begin{tabular}{llll} 
Combination of cases & $\begin{array}{l}\text { Principal diagnosis (ICD-10 } \\
\text { code) }\end{array}$ & $\begin{array}{l}\text { DAS (significant associated } \\
\text { diagnosis) (ICD-10 code) }\end{array}$ & Acts of FCCMA (FCCMA code) \\
\hline First & Specific code & Unspecific code & - \\
Second & Specific code & - & Specific act \\
Third & - & Unspecific code + specific code & - \\
Fourth & - & Unspecific code & Specific act \\
Fifth & - & Specific code & Specific act \\
Sixth & Unspecific code & Specific code & - \\
Seventh & Unspecific code & - & Specific act \\
\hline
\end{tabular}

DAS, Diagnostic Associé Significatif; EAIRP, endoarterial interventional radiology procedures; FCCMA, French Common Classification of Medical Acts; ICD-10, International Classification of Diseases, Tenth Revision. 


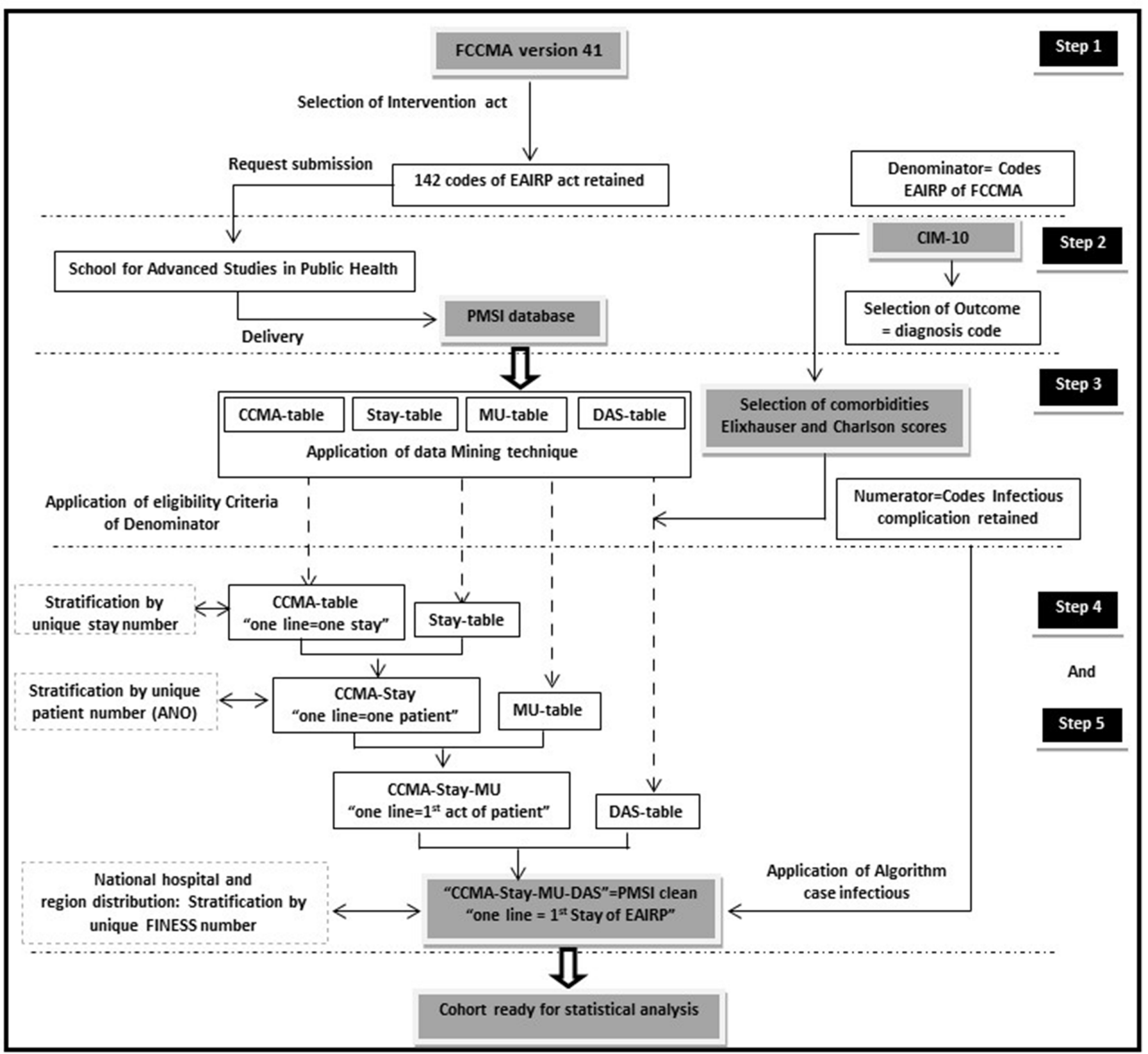

Figure 2 Flow chart of the various stages of exploitation protocol of the PMSI database for EAIRP. DAS, Diagnostic Associé Significatif; EAIRP, endoarterial interventional radiology procedures; FCCMA, French Common Classification of Medical Acts; FINESS, Fichier d'Identification National des Etablissements Sanitaires et Sociaux; MU, medical unit; PMSI, Programme de Médicalisation des Systèmes d'Information.

\section{The 'CCMA' table}

It contains codes providing the reasons for hospitalisation and procedures that the patients received. These codes need to be carefully used and interpreted while taking into account regular updating of FCCMA versions. It is major to check all FCCMA codes used to ensure the codes are in effect during the time period studied. This table will serve EAIRP's identification and application of eligible criteria proper to the denominator. We will proceed to the creation of a 'stay' file. The unit of analysis is the hospital discharge. This means that a person who is admitted to the hospital at multiple times in 1 year will be counted each time as a separate discharge from the hospital.

\section{The 'Stay' table}

It includes clinical and resource use information typically available from discharge abstracts. This hospital-level file contains one observation for each hospital included in the PMSI and contains linkage data elements. We will merge the 'CCMA' and 'stays' tables. The unit of analysis will be patient hospitalisation. For hospital, the unit of analysis will be the National Number of Hospital Identification 
(Fichier d'Identification National des Etablissements Sanitaires et Sociaux).

\section{The 'MU' table}

It contains information from disease severity measures (type of MU, SAPS II). We will merge the 'CCMA-Stays' and 'MU' tables. The objective of this stage is to identify the first stays with an EAIRP. This stage will create a 'patient' file whose unit of analysis is the first act of EAIRP during the target period.

\section{The 'DAS' table}

It contains data derived from the ICD-10 classification. We will pool the three tables previously merged with 'DAS' table. For each patient we will select all hospitalisations following the stay for the first EAIRP. One admission per patient will be used in this study. For multiple admissions, only the first one will be considered and analysed. The objective of this stage is the final file creation called 'PMSI_clean'. To this file, we will apply the algorithm of ICs. This database is the ultimate stage of the various steps of cleaning, selection and validation of variables.

\section{The 'Cohort' database}

It contains both the denominator and the numerator. This file represents the basis for statistical analysis (figure 2).

\section{Statistical analysis}

Descriptive statistics will be used to summarise the data from people with identified IC and the non-IC population. We will compare demographics, smoking habits, comorbidities, category of admission (scheduled or non-scheduled), discharge status, multivariable-adjusted outcomes of hospital status (private or public), death and IC, as well as the combined outcome of death and IC. The severity of inpatients' health status after EAIRP will be measured (length of hospital stay, type of MU and SAPS II). The categorical variables will be expressed as frequencies (percentage) and the quantitative variables as mean (SD) or median (IQR) for non-normally distributed variables. Dichotomous variables will be analysed with $\chi^{2}$ test or Fisher's exact test as appropriate. Bivariate analyses according to infection status (yes/no) will be based on binomial regression as appropriate (Pearson's $\chi^{2}$ test and analysis of variance). Relative risk or OR and $95 \%$ CI will be calculated. Trends will be analysed using the Cochran-Armitage test of linear trend and will be reported as a two-sided $p$ value with significance at 0.05 . We will evaluate changes in procedure volume and associated IC over time. To test IC of treatment effects, we will perform logistic regression. Multivariable logistic regression will be adjusted for the variables gender, age, and comorbid conditions of $\mathrm{CV}$ disease (cardiac arrhythmias, valvular disease, congestive heart failure, peripheral vascular disease, cerebrovascular disease, myocardial infraction and peripheral circulation disorders), renal failure, diabetes, hypertension and chronic obstructive pulmonary disease. For each endpoint, we will report the difference between groups with its $95 \% \mathrm{CI}$ or SE of the mean and $p$ value. Data records with missing values will be analysed. Whenever data will contain missing values, we will try imputation to test whether the results are sensitive to the missing values. The model of multiple imputation $\mathrm{M}$ with Rubin's rules ${ }^{54}$ will be pooled to form a single estimate for each parameter and its SE. Data manipulation and analysis will be performed with STATA V.14.2.

\section{DISCUSSION}

The problems and pathologies that endovascular therapy seeks to remedy are some of today's most common chronic medical problems. ${ }^{55}$ Medically, these procedures decrease risk to patients and allow a quicker return to normal daily functions. ${ }^{55}$ Therefore, this research is timely and clinically important since EAIRP is being performed increasingly and long-term effects remain undetermined..$^{25}$ Surveillance of HAIs is widely recognised as an important instrument in infection control programmes. ${ }^{5}$ Recently some works starting from the Nationwide Inpatient Sample have been undertaken in US states to evaluate interventional endovascular treatment. ${ }^{5657}$ In France, this work will allow evaluation of EAIRP through the use of PMSI over 4 years, thanks to the linking of hospital stay. ${ }^{36}$

The EAIRP national cohort is based on a census of discharges in short-term care, from all hospitals, private and public, practising vascular IR. These specialties include $^{58} 59$ vascular interventional radiologist, interventional cardiologists, interventional neurologists and vascular surgeons. Because endovascular technologies are of multispecialty interest, a review of the entire scope of fundamental information with regard to each aspect of the field is required to furnish a comprehensive review that will provide specific utility for individuals from different disciplines. ${ }^{60}$

The PMSI can be used to examine the use of hospital health services, practice variation, cost and the impact of health policy interventions in the inpatient setting. Use of these population-based data permits investigations with adequate power which would not be possible with more limited single-site clinical data. Moreover, these data are easily accessible and inexpensive, and can be analysed using ubiquitous statistical programs. In this context, research publications from the PMSI data have grown rapidly in recent years.

The utility of administrative data depends on the measures studied and how well they are captured in administrative and clinical records. Careful study design, appropriate database selection and rigorous analyses allow investigators to answer key clinical questions. All of these steps require a thorough understanding of the individual composition and links between databases (CCMA, Stay, MU and DAS), including strengths and limitations between them. There will be several limitations to the present study. 
The first limitation is the retrospective nature of the study, which has significant potential for selection bias. The second limitation is the risks inherent to coding error. The third limitation is that the PMSI compiles billing information which was not originally created for clinical research. ${ }^{31}$ Hence, unbilled procedures or those which do not affect reimbursement directly may not be captured or may be prone to variation in coding practices. ${ }^{61}$ So the specification of the causative micro-organism of certain infections is non-exhaustively indicated in practice. Because of the nature of the PMSI, the medical teams in charge of coding in healthcare institutions seek mainly to promote financial acts realised in their establishments by coding. So the quality and reliability of the stays' coding via the PMSI will be discussed.

The future of healthcare surveillance will involve the capture and use of data from existing electronic databases. ${ }^{19}$ Knowledge on the database's structure and the scalable follow-up of the variables contained in the PMSI database are highly necessary for a reliable epidemiological assessment. The protocol's use and its personalisation for epidemiological studies must be clearly stated. In conclusion, we propose a protocol of analysis of the French medicoeconomic database to assess the epidemiology of adverse infectious events following therapeutic endoarterial IR. We chose this database because it is the only one to encompass all hospital stays at the national level. While the PMSI was not designed primarily to perform research on epidemiology, based on previous utilisations, the present protocol should allow us to get sound data on the issue. If this is confirmed, this study could help design a routine assessment of events following therapeutic endoarterial IR.

\section{Author affiliations \\ ${ }^{1}$ Center of Doctoral Studies, Universite Ibn Tofail Kenitra Faculte des Sciences, Kenitra, Morocco \\ ${ }^{2}$ Public Health, French School for Advanced Studies in Public Health (EHESP), Rennes, France \\ ${ }^{3}$ CPias, Center of Support for the Prevention of the Infections Associated with Care Paris 14, Paris 14, Île-de-France, France \\ ${ }^{4}$ Public Health, Pierre \& Marie Curie faculty of medicine, Sorbonne universities, Paris, île-de-France, France \\ ${ }^{5}$ Department of Intensive Care, Rouen University Hospital, Rouen, France \\ ${ }^{6}$ Rouen University, Faculty of medecine and Pharmacy, Rouen, France}

Acknowledgements We wish to thank Pr Abousaleh Youssef, Dr Oumou Maiga and Juliette Misset for their valuable inputs and for proof-reading the manuscript. We thank the CPias team in Paris for their support and reception.

Contributors AKM and BM contributed to the study concept and design. FG will carry out the retrieval of PMSI database. AKM, BM, PA and AS developed the methods of the review, including the search strategy. All of the authors were involved in the critical revision of the manuscript for important intellectual content. All authors read and approved the final manuscript.

Funding This research received no specific grant from any funding agency in the public, commercial or not-for-profit sectors.

Competing interests None declared.

Patient consent for publication Not required.
Provenance and peer review Not commissioned; externally peer reviewed.

Open access This is an open access article distributed in accordance with the Creative Commons Attribution Non Commercial (CC BY-NC 4.0) license, which permits others to distribute, remix, adapt, build upon this work non-commercially, and license their derivative works on different terms, provided the original work is properly cited, appropriate credit is given, any changes made indicated, and the use is non-commercial. See: http://creativecommons.org/licenses/by-nc/4.0/.

\section{REFERENCES}

1. Shanthi Mendis, World Organization. Pekka Puska, World Heart Federation. Bo Norrving WSO. Global Atlas on Cardiovascular disease prevention and control. Glob atlas Cardiovasc Dis Prev Control 2011:155.

2. Aouba $A$, Rey G. L'évolution de la mortalité et des causes de décès entre 1990 et 2009. Adsp 2012;80:24-8.

3. Tuppin $P$, Rivière $S$, Rigault $A$, et al. Prevalence and economic burden of cardiovascular diseases in France in 2013 according to the national health insurance scheme database. Arch Cardiovasc Dis 2016;109:399-411.

4. Bikfalvi A. Encyclopedic reference of vascular biology \& pathology. illustrée. I'Université du Michigan: Springer, 2000. https://books. google.fr/books?id=Hd_rCAAAQBAJ\&pg=PA31\&lpg=PA31\&dq= $\mid \mathrm{ld}+$ activates+endothelial+cells\&source=bl\&ots=Y4V4ANW1AL\& sig=oD8m1usEWa2vn8z2SvT9GMS4Kuc\&hl=en\&sa=X\&ei=yH2J VabCMo6kyASWt7vADQ\&redir_esc $=y \# v=$ onepage $\& q=|d| \%$ 2520activates\%2520endothelial\%2520c. (Accessed 25 Feb 2018).

5. Walker TG, Kalva SP, Yeddula K, et al. Clinical practice guidelines for endovascular abdominal aortic aneurysm repair: Written by the standards of practice committee for the society of interventional radiology and endorsed by the cardiovascular and interventional radiological society of europe and the canadian interventional radiology association. J Vasc Interv Radiol 2010;21:1632-55.

6. Holmstedt CA, Turan TN, Chimowitz MI, et al. Atherosclerotic intracranial arterial stenosis: risk factors, diagnosis, and treatment. Lancet Neurol 2013;12:1106-14.

7. Manzil AS, Vala S, Vala S. Percutaneous vascular closure device of the femoral access site after coronary interventions for acute coronary syndrome -immediate and short term followup. International Journal of Research in Medical Sciences 2017;5:778-81.

8. Adam A. The definition of interventional radiology (or, 'When is a barium enema an interventional procedure?'). Eur Radiol 1998;8:1014-5.

9. Joffre F. Présentation de la radiologie interventionnelle en France en 2010. J Radiol 2011.

10. Hardman RL, Rochon PJ. Role of interventional radiologists in the management of lower extremity venous insufficiency. Semin Intervent Radiol 2013;30:388-93.

11. Société Française de Radiologie. La radiologie interventionnelle en france. $2011 \mathrm{http} / /$ www.sfrnet.org/rc/org/sfrnet/htm/Article/ 2011/htm-20110201-160438-609/src/htm fullText/fr/Pr\%C3\% A9sentation\%20RI\%20en\%20france\%20en\%202010\%20V2.pdf (Accessed 24 Feb 2018).

12. Société française de radiologie médicale. Hygiène en radiologie interventionnelle: présentation d'un guide de bonnes pratiques. $J$ Radiol 2002;83:351-9.

13. Baerlocher MO, Kennedy SA, Ward TJ, et al. Society of Interventional Radiology: Resource and Environment Recommended Standards for IR. J Vasc Interv Radiol 2017;28:513-6.

14. Kirkwood ML, Arbique GM, Guild JB, et al. Surgeon education decreases radiation dose in complex endovascular procedures and improves patient safety. J Vasc Surg 2013;58:715-21.

15. Malavaud S, Joffre F, Auriol J, et al. Hygiene recommendations for interventional radiology Abbreviations. Elsevier Masson 2012;93.

16. Chabbert V, Otal P, Bouchard L, et al. Midterm outcomes of thoracic aortic stent-grafts: complications and imaging techniques. $J$ Endovasc Ther 2003;10:494-504.

17. Mellouk Aid K, Tchala Vignon Zomahoun H, Soulaymani A, et al. MOrtality and infectious complications of therapeutic EndoVAscular interventional radiology: a systematic and meta-analysis protocol. Syst Rev 2017;6:89.

18. Camou F, Legout L, Caillon J, et al. Traitement des infections de prothèse vasculaire. Réanimation 2016;25:296-307.

19. Tokars JI, Richards C, Andrus M, et al. The changing face of surveillance for health care-associated infections. Clin Infect Dis 2004;39:1347-52.

20. Apte M, Landers T, Furuya $\mathrm{Y}$, et al. Comparison of two computer algorithms to identify surgical site infections. Surg Infect 2011;12:459-64. 
21. Meyerson SL, Feldman T, Desai TR, et al. Angiographic access site complications in the era of arterial closure devices. Vasc Endovascular Surg 2002;36:137-44.

22. Darouiche RO. Treatment of infections associated with surgical implants. N Engl J Med Overseas Ed 2004;350:1422-9.

23. FitzGerald SF, Kelly C, Humphreys H. Diagnosis and treatment of prosthetic aortic graft infections: confusion and inconsistency in the absence of evidence or consensus. J Antimicrob Chemother 2005;56:996-9.

24. Homer-Vanniasinkam S. Surgical site and vascular infections: treatment and prophylaxis. Int $J$ Infect Dis 2007;11 Suppl 1:S17-S22.

25. Wardlaw JM, Chappell FM, Best JJ, et al. Non-invasive imaging compared with intra-arterial angiography in the diagnosis of symptomatic carotid stenosis: a meta-analysis. Lancet 2006;367:1503-12.

26. Eapen ZJ, McBroom AJ, Gray R, et al. Priorities for comparative effectiveness reviews in cardiovascular disease. Circ Cardiovasc Qual Outcomes 2013;6:139-47.

27. Otal P, Auriol J, Chabbert V, et al. Radiologie interventionnelle et traumatismes thoraco-abdomino-pelviens. $J$ Radiol 2008;89:1855-70.

28. CIRCULAIRE DH/PMSI N 96-495 du 6 août 1996 relative aux conditions d'utilisation des données issues du PMSI pour la fixation des budgets 1997 des établissements de santé publics et privés sous dotation globale. Ministère du Trav des Aff Soc Dir DES HÔPITAUX 1995;9 https://www.atih.sante.fr/sites/default/files/public/ content/990/Cir_6-8-96.pdf.

29. Al Kazzi ES, Lau B, Li T, et al. Differences in the Prevalence of Obesity, Smoking and Alcohol in the United States Nationwide Inpatient Sample and the Behavioral Risk Factor Surveillance System. https://www.ncbi.nlm.nih.gov/pmc/articles/PMC4633065/ pdf/pone.0140165.pdf (Accessed 12 Mar 2018).

30. Vasculaire LA, En C. Évaluation de la qualité métrologique des données du PMSI concernant l'accident vasculaire cérébral en France. 2016:8-15.

31. Michèle Kirry C. Guide méthodologique de production des informations relatives à l'activité médicale et à sa facturation en médecine, chirurgie, obstétrique et odontologie- Annexe II de l'arrêté du 20 janvier 2009. Bull Off No 2009/5 bis Fasc spécial-MINISTĖRE LA SANTÉ DES Sport 2009:108 http://solidarites-sante.gouv.fr/IMG/ pdf/ste_20090005_0001_p000.pdf.

32. Pinaire J, Rabatel J, Azé J, et al. Recherche et Visualisation de trajectoires de patients Recherche et visualisation de trajectoires dans les parcours de soins des patients ayant eu un infarctus du myocarde. 2015 https://hal.archives-ouvertes.fr/hal-01180416/ document (Accessed 16 Feb 2018).

33. Vergnenègre $A$, Druet-Cabanac RR M. Radiologie interventionnelle et programme de médicalisation des systèmes d' information (PMSI) : Quelles Conséquences pour un service de Radioloie? J Radiol 1999;80:565-8.

34. States AU. Congress Office Of Technology. Diagnosis related groups (DRGS) and the Medicare Program: implications for medical technology - a technical memorandum.Publicatio. Washington DC: Congress of the U.S. Office of Technology Assessment; For sale by the Supt. of Docs. U.S. G.P.O, 1983. https://www.princeton.edu/ ota/disk3/1983/8306/830610.PDF. (Accessed 27 Feb 2018).

35. Maladie $U$ nationale des caisses d'assurance. Nomenclature generale des actes professionnels (ngap) restant en vigueur depuis la decision uncam du 11 mars 2005. Paris, 2005. http://www.csmf. org/upload/File/CCAM/NGAP_oct2009.pdf. (Accessed 27 Feb 2018).

36. Bocquier A, Thomas N, Zitouni J, et al. Évaluation de la qualité du chaînage des séjours hospitaliers pour l'étude des variations spatiales de santé à partir des données du PMSI. Étude de faisabilité dans trois régions françaises. Revue d'Épidémiologie et de Santé Publique 2011;59:243-9.

37. Goldberg M, Quantin C, Guéguen A, et al. Bases de données médico-administratives et épidémiologie : intérêts et limites. Courr Des Stat - Insee 2008;124:59-70.

38. Legifrance. Version électronique authentifiée publiée au $\mathrm{JO}^{\circ}$ 0160 du 13/07/2018 | Legifrance. J Off La République Française 2018:110-49.

39. Ministère_des_Affaires_Sociales_et_de_la_Santé. Classification Statistique Internationale Des Maladies Et Connexes Cim-10 Fr Á Usage Pmsi. Bull Off 2015;1. Fascicule spécial http://www.atih.sante. $\mathrm{fr} / \mathrm{sites} /$ default/files/public/content/2665/cim10_2015_final_0.pdf.
40. Carlet J, Cavallo J-D, Ceretti A-M, et al. Actualisation de la définition des infections nosocomiales. Définitions des infections associées aux soins. DHOS/DGS/Ministère la santé 2007;43 http://solidaritessante.gouv.fr/IMG/pdf/rapport_complet.pdf.

41. Venkatesan AM, Kundu S, Sacks D, et al. Practice guidelines for adult antibiotic prophylaxis during vascular and interventional radiology procedures. Written by the Standards of Practice Committee for the Society of Interventional Radiology and Endorsed by the Cardiovascular Interventional Radiological Society of Europe and Canadian Interventional Radiology Association [corrected]. $J$ Vasc Interv Radiol 2010;21:1611-30.

42. Société française d'anesthésie et de Réanimation. Antibioprophylaxie en chirurgie et médecine interventionnelle (patients adultes). Actualisation 2010. Ann Fr Anesth Reanim 2011;30:168-90.

43. Zarrinpar A, Kerlan RK Jr. A guide to antibiotics for the interventional radiologist. Semin Intervent Radiol 2005;22:69-79.

44. Agence Technique de l'infomation sur L'hospitalisation. Fascicule de codage pour le pmsi maladies infectieuses. 2014 http://www. departement-information-medicale.com/wp-content/uploads/2014/ 12/fascicule_codage_mal_infect_2014.pdf (Accessed 16 Feb 2018).

45. Grammatico Guillon L, Baron S, Gettner S, et al. Surveillance hospitalière des infections ostéo-articulaires en France: analyse des données médico-administratives, PMSI 2008. Bull Epidémiologique Hebd 2013;LIV:39-44.

46. Grammatico-Guillon L, Baron S, Gaborit C, et al. Quality assessment of hospital discharge database for routine surveillance of hip and knee arthroplasty-related infections. Infect Control Hosp Epidemiol 2014;35:646-51.

47. Daideri G, Berthier F, Gendreike Y. Qualité de l'information médicale : le codage des infections nosocomiales dans les secteurs de soins critiques à l'hôpital. Hygiènes Rev Off la Société Fr d'hygiène Hosp 2005;13, n 5:375-80 http://www.bdsp.ehesp.fr/Base/339270/.

48. Charlson ME, Pompei P, Ales KL, et al. A new method of classifying prognostic comorbidity in longitudinal studies: development and validation. J Chronic Dis 1987;40:373-83.

49. Elixhauser A, Steiner C, Harris DR, et al. Comorbidity measures for use with administrative data. Med Care 1998;36:8-27.

50. Quan H, Sundararajan V, Halfon P, et al. Coding Algorithms for Defining Comorbidities in ICD-9-CM and ICD-10 Administrative Data. Med Care 2005;43:1130-9 http://czresearch.com/dropbox/Quan_ MedCare_2005v43p1130.pdf.

51. Sundararajan V, Henderson T, Perry C, et al. New ICD-10 version of the Charlson comorbidity index predicted in-hospital mortality. J Clin Epidemiol 2004;57:1288-94.

52. Fuhrman C. Surveillance épidémiologique de la multimorbidité : revue bibliographique: Saint- Maurice cedex: InVS (Institut de veille sanitaire), 2014. http://www.invs.sante.fr/Publications-et-outils/ Rapports-et-syntheses/Maladies-chroniques-et-traumatismes/2014/ Surveillance-epidemiologique-de-la-multimorbidite. (Accessed 16 Feb 2018).

53. Teebken OE, Bisdas T, Assadian O, et al. Recommendations for reporting treatment of aortic graft infections. Eur J Vasc Endovasc Surg 2012;43:174-81.

54. Little RJA, Rubin DB. Statistical analysis with missing data: Wiley, 2002. https://www. wiley.com/en-us/Statistical+Analysis+with+ Missing+Data\%2C+2nd+Edition-p-9780471183860. (Accessed 13 Mar 2018).

55. White RA, Fogarty TJ. Peripheral Endovascular Interventions. New York: Springer, 1999

56. Steiner C, Barrett M, Weiss A. HCUP Projections: Cardiovascular/ Cerebrovascular Conditions and Procedures 2001 to 2012, 2012.

57. Khera R, Cram P, Vaughan-Sarrazin M, et al. Use of Mechanical Circulatory Support in Percutaneous Coronary Intervention in the United States. Am J Cardiol 2016;117:10-16.

58. Sunshine JH, Lewis RS, Bhargavan M. A Portrait of Interventional Radiologists in the United States. American Journal of Roentgenology 2005;185:1103-12.

59. Philippe M, Marc V, h Marc V, et al. la radioprotection des Patients Et des travailleures en radiologie Interventionnelle Et Au Bloc Opératoire. Radioprotection 2011:27-33.

60. Fogarty TJ, White RA. Peripheral endovascular interventions. Rodney A, White MD, eds. USA: Harbor- UCLA Medical Center. W.Carson ST.1000 Torrance 90509, 2010.

61. Khera R, Krumholz HM. With great power comes great responsibility: Big data research from the national inpatient sample. Circ Cardiovasc Qual Outcomes 2017;10:1-5. 